\title{
Application of the Equipment Replacement Dynamic Programming Model in Conveyor Belt Replacement: Case Study of a Gold Mining Company
}

\section{David C. Zvipore}

Department of Statistics and Operations Research, National University of Science and Technology, Zimbabwe

Email: davezvipore@gmail.com

\section{Philimon Nyamugure}

Department of Statistics and Operations Research, National University of Science and Technology, Zimbabwe philimon.nyamugure@nust.ac.zw

Daniel Maposa*

School of Mathematical and Computer Sciences, University of Limpopo, South Africa Email:danmaposa@gmail.com

'Maseka Lesaoana

School of Mathematical and Computer Sciences, University of Limpopo, South Africa

Email: maseka.lesaoana@ul.ac.za

Doi:10.5901/mjss.2015.v6n2s1p605

\section{Abstract}

As assets age, they generally deteriorate, resulting in rising operating and maintenance costs and decreasing salvage values. In this paper a comprehensive Dynamic Programming-based optimisation solution methodology is used to solve the equipment replacement optimisation problem on the replacement of conveyor belts at a Gold Mining company in Zimbabwe. Given a mining setup with one and two-year old conveyor belts the ultimate objective is to keep or replace the conveyor belt such that the overall cost of material handling is minimised within a five-year period. The findings reveal that this mining system should replace conveyor belts yearly. It is concluded that, an equipment replacement policy for conveyor belts is a necessity in a mining system so as to achieve an optimal contribution to the economic value that a mining system may accrue within a period of time.

Keywords: Dynamic programming; replacement; conveyor belt; equipment replacement optimization.

\section{Introduction}

In this paper we develop a comprehensive Dynamic Programming-based optimization solution methodology to solve the equipment replacement optimization (ERO) problem on the replacement of conveyor belts at a Gold Mining company in Zimbabwe. In this study, a conveyor belt is regarded as a machine comprising of the rollers, mountings and rubber lining.

Mitchell (1998) asserts that replacement theory seeks to answer the question: What is the optimum economic life of this piece of equipment? According to Vorster (2006) surface mining equipment has a finite life. Eschenbach (2003) identified five reasons for the replacement of equipment, and these are: reduced performance of ageing equipment, altered requirements for using the equipment, obsolescence due to a new improved model, the risk of catastrophic failure or unplanned replacement, and item shifts between renting, leasing and owning. Surface earthmoving equipment is classified as a fixed asset and replacements are funded from capital expenditure budgets. Therefore the Return of Investment (ROI) is maximised when replacement occurs at the optimal economic life of the equipment (Mellal et al., 2013; Fallahnezhad et al., 2014 Gress et al., 2014). The economic life is defined as the age that minimises the average owning and operating costs (Mitchell, 1998; Fan et al., 2011; Rahimdel et al., 2013; Fallahnezhad et al., 2014). This includes the purchase, operating and maintenance cost, less any salvage value (du Plessis, 2007).

The mining company management needs to determine the optimal revenue that may be accrued in their mining 
system that uses conveyor belts if they consider a keep-and-replace decision on those belts that need replacement within a five-year period.

The primary aim of this study is to assess the economic value that a mining system may accrue due to conveyor belt replacement using the Equipment Replacement Dynamic Programming (ERDP) model as a decision making tool.

\subsection{Objectives}

The specific objectives of the study are as follows:

- To determine the most economic age of a conveyor belt in the mining system.

- To calculate the maximum net income that is gained by the mining system through a 'Keep or Replace' decision on conveyor belts within the five-year period.

- To ascertain the optimal decision making policy of 'Keeping or Replacing' a conveyor belt in the mining system within a five-year period of its lifetime.

- To design a system of calculating approximate revenue in a mining system accrued from the replacement of conveyor belts.

\subsection{Signifcance and delimitations of the study}

The significance of this study is two-fold, that is:

- The study will assist in decision making which contributes to the operating expenses of conveyor belt equipment for mining companies in Zimbabwe. This could be extended to similar companies in other countries globally.

- The study will result in the overall cost of materials handling being reduced at the mining company and other related companies in the Zimbabwean economic context.

The delimitations of this study are as follows:

- This particular study focuses on the replacement of conveyor belts only in a mining machinery setup.

- The decision making process takes into consideration a five-year period.

\subsection{Assumptions of the study}

The findings in this paper are based on the following assumptions:

- There is no technological change over an infinite horizon. This means that the conveyor belt will continue to be needed up to the end of the planning period.

- The decision to keep or replace a conveyor belt may be made at each yearly period after assessment of its operation.

- There is an operational risk cost of a conveyor belt which changes in yearly periods of time and it determines the decision to replace the conveyor belt.

- The conveyor belt is assumed to operate continuously over the period of analysis and not affected by natural disasters and accidents.

- Inflationary changes in prices are ignored during the period of equipment replacement consideration.

- Once the economic age of a conveyor belt has been determined, the asset should be continuously replaced at this age under the assumption of repeatability and stationary costs (Hartman and Rogers, 2006; Fan et al., 2013).

The rest of the paper is such that section 2 deals with research methodology, section 3 deals with the determination of the input parameters of ERO problem, section 4 gives the findings and discussion, while section 5 gives the concluding remarks and recommendations.

\section{Research Methodology}

This section gives a detailed account of the materials and methods used in this study.

\subsection{The equipment replacement model}

The longer a machine stays in service, the higher is its maintenance cost, and the lower its productivity (Fan et al., 2013; Rahimdel et al., 2013; Fallah et al., 2014). When a machine reaches a certain age, it may be more economical to replace 
it. The problem thus reduces to determining the most economical age of a machine (Bellman, 1995; Yun and Kaio, 2013).

Suppose that we are studying the machine replacement problem over a span of $n$ years. At the start of each year, we decide whether to keep the machine in service for an extra year or to replace it with a new one. Let $r(t), c(t)$ and $s(t)$ represent the yearly revenue, operating cost, and salvage value of a ${ }^{t \text {-year }}$ old machine, respectively. The cost of acquiring a new machine in any year is $I(T a h a, 2007)$. The elements of the Dynamic Programming (DP) model are:

Stage $i$ is represented by year $i, i=1,2, \ldots, n$.

The alternatives at stage (year) $i$, call for either keeping or replacing the machine at the start of year $i$. The state at stage $i$ is the age of the machine at the start of year $i$.Given that the machine is $t$ years old at the start of year $i$, define

$f_{i}(t)=$ maximum net income for years $i, i+1, \ldots$, and $n$.

The recursive equation is derived as

$$
\begin{aligned}
& f_{i}(t)=\max r(t)-c(t)+f_{i+1}(t+1), \text { for KEEP } \\
& f_{i}(t)=\max r(0)+s(t)-I-c(0)+f_{i+1}(1), \text { for REPLACE } \\
& f_{n+1}(.)=0
\end{aligned}
$$

\subsection{The Gold Mine conveyor belt system}

The Gold Mine shaft plant that has been taken into consideration has seven conveyor belts which are interconnected by various stations. All these conveyor belts carry virtually the same weight hence their operation costs and revenue are approximately the same. The current set of conveyor belts comprises of one-year old and two-year old conveyor belts.

\section{Determination of the Input Parameters for the ERO Problem}

The Plant Engineer requires that a five-year old conveyor belt be replaced. The cost of a new conveyor belt set (including replacement costs) is about US\$9500. In deriving the revenue of an operational conveyor belt, we determined the revenue generated by the plant system per day since the downtime of a conveyor belt ultimately results in the loss of this same amount of revenue each day. The mining system operates virtually every day for fifty-two weeks in a year, making an average of US $\$ 5000$ per day for a seven-day week period. This amounts to about US\$1 820000 per annum. This is the revenue of a new conveyor belt; it is assumed that it decreases by about twenty percent every year due to incorporating the risk factor. The operating cost of a conveyor belt involves mainly the running costs of power and lubrication, which amount to about US $\$ 500$ per day. In a fifty-two week year, at seven days a week, the annual operating costs of the conveyor belt add up to about US\$182 000. The operating cost of a new conveyor belt is assumed to increase by about thirty percent each year due to increase in service requirements as the piece of equipment gets older. Used conveyor belts are mostly purchased by minor mining ventures that mostly use them as shock absorber washers on stamp-mills, else they are sold to small-traders who make door mates. The mine management assume that they can approximately get about US\$2 750 from selling a one-year old conveyor belt, and this price decreases by about ten percent as the belt gets older each year.

Table 1 shows the summary of data values for the revenue, operating cost and salvage value from a new conveyor belt (less than one year), up to a five-year old conveyor belt.

Table 1: Summary of input values for the revenue, operating cost and salvage value from a new conveyor belt

\begin{tabular}{|cccc|}
\hline Age $(\mathbf{t})$ & Revenue $\mathbf{r}(\mathbf{t})$ & Operating Cost $\mathbf{c}(\mathbf{t})$ & Salvage Value $\mathbf{s}(\mathbf{t})$ \\
\hline $\mathbf{0}$ & 1820000 & 182000 & $\mathrm{XXXX}$ \\
$\mathbf{1}$ & 1456000 & 236600 & 2750 \\
$\mathbf{2}$ & 1164800 & 397580 & 2475 \\
$\mathbf{3}$ & 931840 & 399854 & 2228 \\
$\mathbf{4}$ & 745472 & 519810 & 2005 \\
$\mathbf{5}$ & 596378 & 675753 & 1804 \\
\hline
\end{tabular}

Key: $x x x x$ means that there is no salvage value for a conveyor belt less than a year old.

Since the current set of conveyor belts at the plant comprises of one-year old and two-year old conveyor belts, the determination of the feasible values for the age of the machine at each stage (planning year) is somewhat tricky. 
Appendix 1 (Figure 1) summarises the network diagram representing the problem for the one-year old machines and Appendix 2 (Figure 2) summarises the network diagram representing the problem for the two-year old machines. Solving the equipment replacement optimisation (ERO) problem is equivalent to finding the longest route, that is, the maximum revenue from the beginning of year one to the end of year five. It is quite logical to say that if a conveyor belt is replaced in year five, that is, at the end of the planning horizon, its revenue will include the salvage value, ${ }^{s(t)}$, of the replaced conveyor belt and the salvage value, $s(1)$, of the replacement conveyor belt. A formula coded in Microsoft Excel spreadsheet has been developed to calculate the optimal solutions using equations [1] and [2] at each stage and the output is shown in Table 2 for each case.

\subsection{Case I: Analysis of the One-Year Old conveyor belt ERO problem}

Figure 1 shows the network diagram that summarises the ERO problem for a one-year old conveyor belt. At the start of year one, we have a one-year old conveyor belt. We can either replace it $(R)$ or keep it $(K)$ for another year. At the start of year two, if replacement occurs, the new conveyor belt will be one year old; otherwise the old conveyor belt will be two years old. At the start of year three we have a one-year, a two-year and a three-year old conveyor belt. If we keep the three-year old conveyor belt, it will be four years old in the following year; if we replace it, the new machine will be one year old in the next year. The two-year old conveyor belt, if kept will be three years old in the following year; otherwise if replaced, it will be one year old. For the one-year old conveyor belt, if kept, it will be two years old; otherwise it will be replaced to be a one-year old conveyor belt. At the start of year four, the possible alternatives we have are a one-year old, two-year old, three-year old, and four-year old conveyor belts. For the one-year old conveyor belt, we can decide to keep it, implying that it will be two years at the beginning of the following year, or replace it to be a one-year old machine. For the two-year old conveyor belt, we can keep it to be three years old at the beginning of the following year; or otherwise replace it to be a one-year old conveyor belt. For the three-year old conveyor belt, we may replace it with a new one or otherwise keep it to be a four-year old conveyor belt. For the four-year old conveyor belt, we may keep it to be five years or replace it to be one-year old in the following year. At the start of year five the possible ages of the conveyor belts are one year, two years, three years, four years and five years. For the one-year old conveyor belt, if replacement occurs, the new conveyor belt will be one-year old at the beginning of the following year; otherwise the old conveyor belt will be two years old. For the two-year old conveyor belt, if replacement occurs, the new machine will be one year old a year later; otherwise the old machine will be three years old. For the three-year old conveyor belt, in the same year, if replacement occurs, the new conveyor belt will be one year old; otherwise if we decide to keep the conveyor belt it will be four years old in the beginning of the following year. For the five year old conveyor belt, according to company policy, it must definitely be replaced, and the new conveyor belt will be one year old. The sixth year is the beginning of a new planning horizon and we will not take it into consideration.

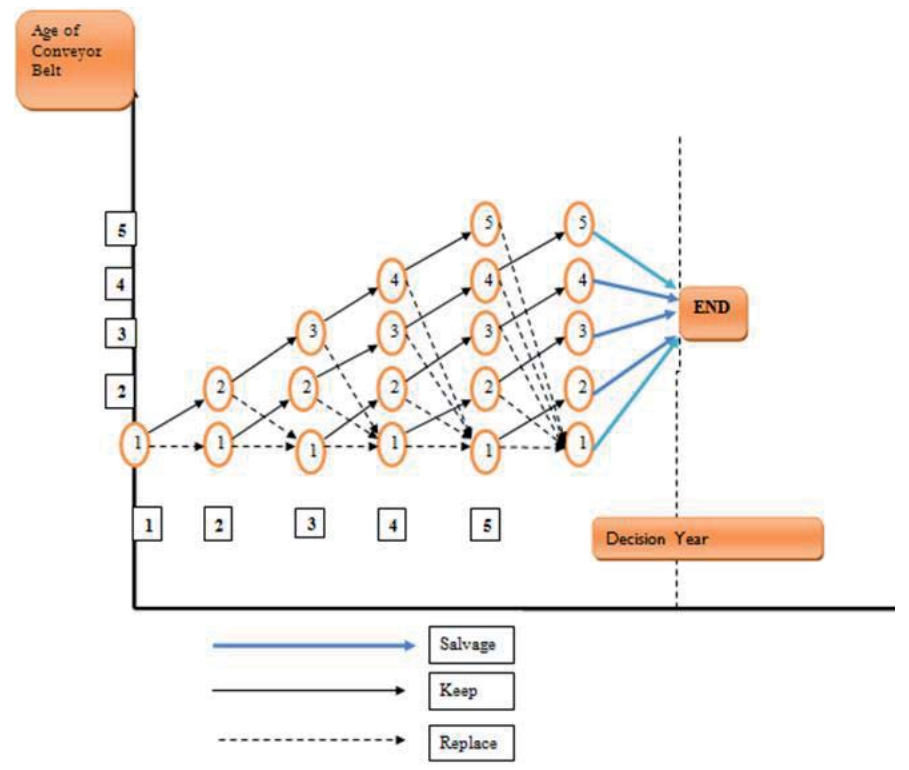

Figure 1: Summary of the network diagram representing the ERO problem for the One-Year Old machines 
Table 2 presents results for the various alternatives as a DP formulation problem.

Table 2: Alternatives in dynamic programming formulation

\begin{tabular}{|c|c|c|c|c|}
\hline Stage 5 & KEEP & REPLACE & Optimal & Solution \\
\hline & $r(t)+s(t+1)-c(t)$ & $r(0)+s(t)+s(1)-c(0)-I$ & $f_{5}(t)$ & Decision \\
\hline $\mathbf{1}$ & $1456000+2475-236600=1221875$ & $1820000+2750+2750-182000-9500=1634000$ & 1634000 & $\mathrm{R}$ \\
\hline $\mathbf{2}$ & $1164800+2228-307580=859448$ & $1820000+2475+2750-182000-9500=1633725$ & 1633725 & $\mathrm{R}$ \\
\hline $\mathbf{3}$ & $931840+2005-399854=533941$ & $1820000+2228+2750-182000-9500=1633475$ & 1633475 & $\mathrm{R}$ \\
\hline $\mathbf{4}$ & $745472+1804-519810227466$ & $1820000+2005+2750-182000-9500=1633255$ & 1633255 & $\mathrm{R}$ \\
\hline $\mathbf{5}$ & Must Replace & $1820000+1804+2750-182000-9500=1633054$ & 1633054 & $\mathrm{R}$ \\
\hline
\end{tabular}

\begin{tabular}{|c|c|c|c|c|}
\hline Stage 4 & KEEP & REPLACE & Optimal & Solution \\
\hline & $r(t)-f_{5}(t+1)-c(t)$ & $r(0)+s(t)+f_{5}(1)-c(0)-I$ & $f_{4}(t)$ & Decision \\
\hline $\mathbf{1}$ & $1456000+1633725-236600=2853125$ & $1820000+2750+1634000-9500-182000=3265250$ & 3265250 & $\mathrm{R}$ \\
\hline $\mathbf{2}$ & $1164800+1633478-307580=2490698$ & $1820000+2475+1634000-182000-9500=3264975$ & 3264975 & $\mathrm{R}$ \\
\hline $\mathbf{3}$ & $931840+1633255-399854=2165241$ & $1820000+2228+1634000-182000-9500=3264725$ & 3264725 & $\mathrm{R}$ \\
\hline $\mathbf{4}$ & $745472+1633054-519810=1858716$ & $1820000+2005+1634000-182000-9500=4895755$ & 4895755 & $\mathrm{R}$ \\
\hline
\end{tabular}

\begin{tabular}{|c|c|c|c|c|}
\hline Stage 3 & KEEP & REPLACE & Optimal & Solution \\
& $r(t)+f_{4}(t+1)-c(t)$ & $r(0)+s(t)+f_{4}(1)-c(0)-I$ & $f_{3}(t)$ & Decision \\
\hline $\mathbf{1}$ & $1456000+3264975-236600=4484375$ & $1820000+2750+3265250-9500-182000=4896500$ & 4896500 & $\mathrm{R}$ \\
\hline $\mathbf{2}$ & $1164800+3264505-307580=4121948$ & $1820000+2475+3265250-182000-9500=4896525$ & 4896525 & $\mathrm{R}$ \\
\hline $\mathbf{3}$ & $931840+3264505-399854=3796491$ & $1820000+2228+3265250-182000-9500=4895978$ & 4895978 & $\mathrm{R}$ \\
\hline
\end{tabular}

\begin{tabular}{|c|c|c|c|c|}
\hline Stage 2 & KEEP & REPLACE & Optimal & Solution \\
\hline & $r(t)+f_{3}(t+1)-c(t)$ & $r(0)+s(t)+f_{3}(1)-c(0)-I$ & $f_{2}(t)$ & Decision \\
\hline $\mathbf{1}$ & $1456000+4896525-236600=6115925$ & $1820000+2750+4896500-9500-182000=6527750$ & 6527750 & $\mathrm{R}$ \\
\hline $\mathbf{2}$ & $1164800+4895978-307580=5660924$ & $1820000+2475+4896500-182000-9500=6527475$ & 6527475 & $\mathrm{R}$ \\
\hline & & & & \\
\hline
\end{tabular}

\begin{tabular}{|c|c|c|c|c|}
\hline Stage 1 & KEEP & REPLACE & Optimal & Solution \\
\hline & $r(t)+f_{2}(t+1)-c(t)$ & $r(0)+s(t)+f_{2}(1)-c(0)-I$ & $f_{1}(t)$ & \\
\hline 1 & $1456000+6527475-236600=7746875$ & $1820000+2750+6527750-9500-182000=8159000$ & 8159000 & $\mathrm{~K}$ \\
\hline
\end{tabular}

The sequence of optimal actions in Table 2 can be read from the previous stages sequentially. An inspection of the stages in Table 2 shows that the original 5-year old, 4-year old, 3-year old, and 2-year old equipment unit should be immediately replaced. This implies that the state (age) of the equipment in service at the start of year two will be zero.

Several other DP related problems have been solved and their results compare well with ours (Mohammad and Seyed 2014; Fan et al., 2014).

\subsection{Case II: Analysis of the Two-Year Old conveyor belt ERO problem}

Figure 2 shows the network diagram that summarises the ERO problem for the two-year old conveyor belts in the plant. At the start of year one, we have a two-year old conveyor belt. If replacement occurs, the new conveyor belt will be oneyear old in the following year; otherwise if kept, it will be three years old in the following year. In year two we have alternatives of a one-year old and a three-year old conveyor belt. For the three-year old conveyor belt, if replacement occurs, the new conveyor belt will be one year old in the following year; otherwise if kept, it will be four years old. For the one-year old conveyor belt, if replacement occurs, it will be one year old by the beginning of the following year, otherwise if kept, it will be two years old. In year three, we have alternatives for a one-year, two-year and four-year old conveyor belts. For the one-year old conveyor belt, if replacement occurs, the new conveyor belt will be one year old in the 
following year; otherwise if kept, it will be two years old at the beginning of the next year. For the two-year old conveyor belt, if replacement occurs, it will be one year old in the following year; otherwise we have a three-year old conveyor belt. For the four-year old conveyor belt, if kept, we have a five-year old conveyor belt in the following year; otherwise if replacement occurs, we have a one-year old conveyor. The five-year old conveyor belt is definitely replaced due to company policy. In the fifth year, the two-year old conveyor belt gives us alternatives for a one-year, two-year, three-year and four-year old conveyor belts. If the one-year old conveyor belt is kept, it will be two years in the following year, but if replacement occurs, it will be one-year old. For the two-year old conveyor belt, if replacement occurs, it will be one-year old in the following year; otherwise if kept, it will be three years old. For the three-year old conveyor belt, if kept, it will be four years old in the following year. For the four-year old conveyor belt, if kept, it will be five years old in the following year; otherwise if replacement occurs it will be one-year old. The sixth year is outside our planning horizon, and we shall not take it into consideration.

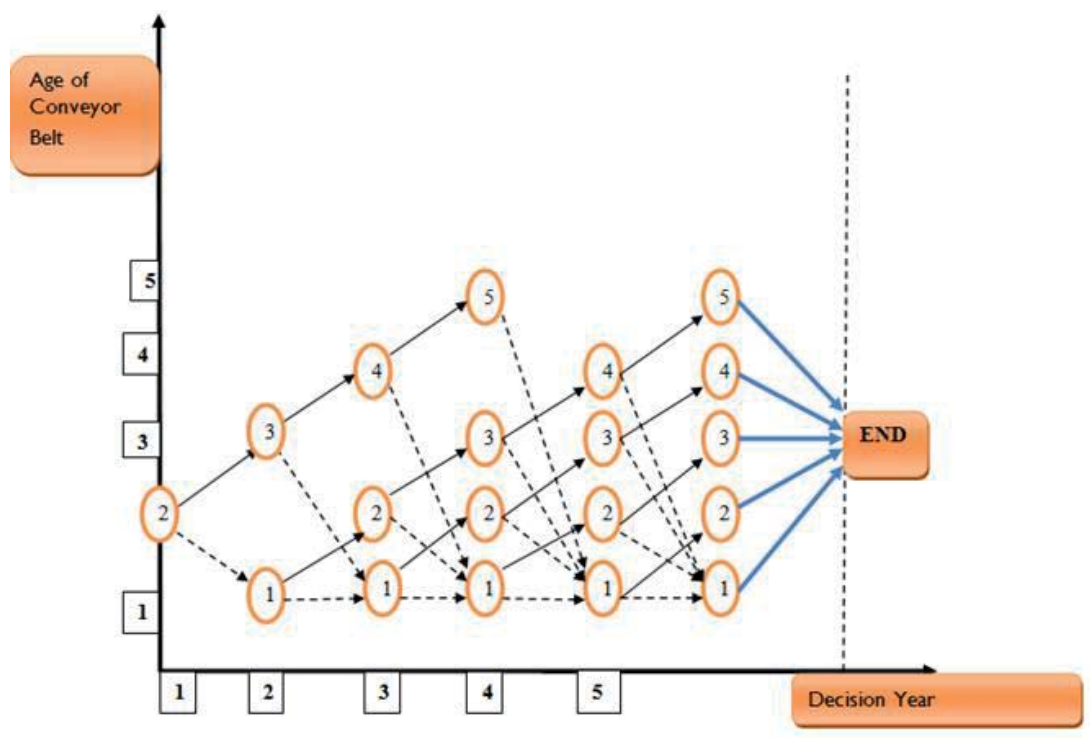

Figure 2: Summary of the network diagram representing the ERO problem for the Two-Year Old machines

Similarly to the one-year old DP formulation in Table 2 the two-year sequence of optimal actions revealed that the original 5-year old, 4-year old, 3-year old, and 2-year old equipment unit should be immediately replaced, but the one-year old conveyor belt can be kept. The subsequent section includes a sensitivity analysis of the study which incorporates various options to be taken into consideration.

\section{Findings and Discussion}

This section gives detailed findings and discusses the results. Sensitivity analysis of the results is also performed in this section.

\subsection{Solution to the One-Year Old conveyor belt ERO problem}

The sequence of optimal actions for the one-year old conveyor belt is presented in Table 2. At the inspection of stage-1, Table 2 shows that the original one-year-old equipment unit should be kept. This implies that the state (age \{t\}) of the conveyor belt equipment unit in service at the start of year two will be two years old. Next, inspection of the second row of stage-2 in Table 2 shows that the equipment unit should be replaced in year two. The first row of stage-3 shows that the new equipment unit should be replaced at the start of year three. Inspection of the first row of stage-4 shows that the equipment unit should be replaced. Finally, the unit of equipment should be replaced at the end of the planning horizon (i.e., the start of year five). Thus, the optimal policy prescribes the following sequence of actions starting from year one: keep, replace, replace, replace and replace. 


\subsection{Solution to the Two-Year Old conveyor belt ERO problem}

For the two-year old conveyor belt, the sequence of optimal actions is similar to that of the one-year old conveyor belt in Table 2. The inspection of stage-1 for two-year old conveyor belt reveals that the original two-year old equipment unit should be immediately replaced. This implies that the state (age $\{t\})$ of the conveyor belt equipment unit in service at the start of year two will be one year old. Next, inspection of the second row of the stage-2 of the two-year old conveyor belt table reveals that the equipment unit should be replaced in year two. The first row of stage-3 of the two-year old conveyor belt table reveals that the new equipment unit should be replaced at the start of year three. Inspection of the first row of stage-4 reveals that the equipment unit should be replaced. Finally, the unit of equipment should be replaced at the end of the planning horizon (i.e., the start of year five). Thus, the optimal policy prescribes the following sequence of actions starting from year one: replace, replace, replace, replace and replace. This results in a total cost of US\$8 158725.

\subsection{Comments on the results of the ERO problem}

Firstly, as model year increases, the non-adjusted original total purchase cost increases noticeably. This is probably due to the fact that as the technology advances, equipment normally gets more expensive and therefore the purchase cost in the absolute dollar values increases along the years (Fan et al., 2012). However, accounting for economy-dependent inflation rate adds more complexities and will therefore make the prediction for the inflation-adjusted total purchase cost less reliable and unpredictable. After adjustment the total purchase cost seems to decrease initially and then increase slightly into the future although the pattern is not very clear (Fan et al., 2012). Secondly, as equipment age increases several things happen; the equipment utilisation decreases, the commit hours decrease, the total operation and maintenance (OM) cost per km/hour increases, and the down time seems to stay flat. This might be due to the fact that as equipment gets older, the risk of equipment being down generally increases and the down time might also increase assuming equal mileage being used (Hartman and Rogers, 2006). On the other hand however, as equipment ages, the equipment utilisation decreases. These two effects cancel each other and that may explain why the down time almost stays the same as equipment ages (Hartman and Rogers, 2006).

\subsection{Sensitivity analysis}

As a model validation technique, a sensitivity analysis was conducted which considers a change (sharp-surge) in operating costs. The realistic approach considers a hundred percent increase in operating costs, while the other variables (revenue and salvage value) remain constant.

A table showing the summary of data values for the revenue, operating cost and salvage value from a new conveyor (less than one year) up to a five-year old conveyor belt was derived and computed in a similar way to Table 1.

The sequence of optimal actions from the solution tables was sequentially assessed after changing the operating costs. Inspection of stage-1 reveals that the original one-year old equipment unit should be immediately replaced. This implies that the state (age $\{t\}$ ) of the conveyor belt equipment unit in service at the start of year two will be one year old. Next, inspection of the first row of the stage-2 table shows that the equipment unit should be replaced in year two. The first row of the stage- 3 shows that the new equipment unit should be replaced at the start of year three. Inspection of the first row of the stage- 4 shows that the equipment unit should be replaced. Finally, the unit of equipment should be replaced at the end of the planning horizon (i.e., the start of year five). Thus, the optimal policy prescribes the following sequence of actions starting from year one: replace, replace, replace, replace and replace. This results in a total cost of US\$72 749000 . The sensitivity analysis has revealed that as the cost of operations increases, the preferable decision is to frequently replace the conveyor belts. This is indeed economically reasonable since we realise that as a machine gets older there is an increase in operating cost. The replace decision also adds the revenue accruing from salvage sales.

\section{Concluding Remarks}

The study has revealed that the most economic age of a conveyor belt in the Gold Mining company system considered in this paper is a one-year old.

The optimal decision making policy of 'Keeping or Replacing' a conveyor belt in this mining system within a fiveyear period of time over its lifetime for the one-year old conveyor belt is to keep it in the first year and replace it yearly for the next four years, and to replace all the two-year old conveyor belts in the system.

The equipment replacement optimisation (ERO) technique can be adopted as a suitable mechanism for calculating 
appropriate revenues in a mining system accrued from the replacement of conveyor belts as compared to simple logic or general management reasoning.

It can be concluded that an equipment replacement policy for conveyor belts is a necessity in a mining system. Hence it is recommended that the Operations Manager considers an analysis of replacement policies on the conveyor belts (and other related machinery) in this mining system so as to achieve an optimal contribution to the economic value that a mining system may accrue within a period of time. Based on the findings of this paper, we recommend to the Gold Mining company considered in this study to replace conveyor belts annually.

\section{References}

Bellman, R. (1995). Equipment replacement policy. Journal of the Society for Industrial and Applied Mathematics, 3(3), pp.133-136.

du Plessis, C. (2007). Replacement of earth moving equipment at surface coal mining operations in South Africa. A Research report submitted to the Gordon Institute of Business Science. University of Pretoria.

Eschenbach, T.G. (2003). Engineering economy: Applying theory to practice. Oxford University Press.

Fallah, M.S., Mostafaeipour, A. and Sajadieh, M.S. (2014). Implementation of traditional (SR)-based PM method with Bayesian inference. International Journal of Industrial Engineering, 25(1), pp.27-32.

Fallahnezhad, M.S., Sajjadieh, M.S. and Abdollahi, P. (2014). An interative decision rule to minimize cost of acceptance sampling plan in machine replacement problem. International Journal of Engineering-Transactions A: Basics, 27(7),1099.

Fan, W.D., Machemehl, R.., Gemar, M. and Brown, L. (2014). A stochastic dynamic programming approach for the equipment replacement optimisation under uncertainty. Journal of Transportation System Engineering and Information Technology, 14(3), pp.76-84.

Fan, W.D., Gemar, M.D. and Machemehl, R. (2013). Equipment replacement decision making: Opportunities and challenges. Journal of the Transportation Research Forum, 52(3), pp.79-90.

Fan, W.D., Machemehl, R.B., and Kortum, K. (2011). Equipment replacement optimization. Transportation Research Record: Journal of the Transportation Research Board, 2220(1), pp.88-98.

Fan, W.D., Gemar, M.D. and Machemehl, R. (2012). Equipment replacement decision making: Opportunities and challenges. Presentation at the 53rd Annual Forum of the Transportation Research Forum, March 15-17, 2012 Annual Forum Conference Proceedings, Tampa, Florida.

Gress, E.S.H., Lechuga, G.P. and Gress, N.H. (2014). Sensitivity analysis of the replacement problem. Intelligent Control and Automation, 5(2),46.

Hartman, J.C. and Rogers, J.L. (2006). Dynamic programming approaches for equipment replacement problems with continuous and discontinuous technological change. IMA Journal of Management Mathematics, 17(2),pp.143-158.

Mellal, M.A., Adjerid, S., Benazzouz, D., Berrazouane, S. and Williams, E.J. (2013). Optimal policy for the replacement of industrial systems subject to technological obsolescence-Using genetic algorithm. Acta Polytechnica Hungarica, 10(1), pp.197-208.

Mitchell, Z.W. (1998). A statistical analysis of construction equipment repair costs using field data and the cumulative cost model. A dissertation submitted to the Faculty of Virginia Polytechnic Institute and State University Blackburg.

Mohammad S.F.N. and Seyed T.A.N. (2014). A multi-stage two-machine replacement strategy using Mixture models, Bayesian inference and Stochastic Dynamic Programming. Comminication in Statistics Theory and Methods. 40(4), pp. 702-725.

Rahimdel, M.J., Hosienie, S.H., Ataei, M. and Khalokakaei, R. (2013). The reliability and maintainability analysis of pneumatic system of rotary drilling machines. Journal of the Institution of Engineers (India): Series D, 94(2),pp.105-111.

Taha, H.A. (2007). Operations research: An introduction. 8th Edition, Pearson, Prentice Hall.

Vorster, M.C. (2006). Keep capacity in stock. Construction Equipment. Available online on: http//www.constructionequipment.com/ article/CA6381099.html?industryid=23397.

Yun, W.Y. and Kaio, N. (2013). Repair-time limit replacement policies. In Stochastic Reliability and Maintenance Modeling, pp.101-121. Springer London. 